\title{
MODERN SHIBORI: BEYOND HANDCRAFTED TRADITION
}

\author{
by \\ Erin L. MacQuarrie \\ BAA, University of New Brunswick, 2015
}

\author{
An MRP \\ Presented to Ryerson University \\ in partial fulfillment of the \\ requirements for the degree of \\ Master of Arts \\ in the Program of \\ Fashion \\ Toronto, Ontario, Canada, 2017 \\ (C) Erin L. MacQuarrie 2017
}




\begin{abstract}
Through practice-led research entitled Modern Shibori: Beyond Handcrafted Tradition, I explore the contemporary relevance of shibori - an ancient Japanese resistdye method - in the context of present day Canada. The research employs a hybrid cultural products framework to aid in the contextualization and analysis of a series of artworks, intended to disseminate concepts related to craft culture and sustainability. The aim of Modern Shibori is to blur the perceived line between craft and fine art and to help encourage continued practice of the ancient textile technique. The outcome of the project is a cohesive body of contemporary work that is explorative, yet pays homage to traditional shibori, and uses materials with low environmental impact.
\end{abstract}

\title{
Acknowledgements
}

I would like to thank everyone who has supported me throughout the process of completing this MRP. I would first like to acknowledge my advisor, Henry Navarro Delgado, for his constant encouragement and feedback. I also wish to thank the Yeates School of Graduate Studies and Ryerson's School of Fashion, who’s financial assistance made it possible for me to attend the $10^{\text {th }}$ International Shibori Symposium in Oaxaca, Mexico. Thank you to the instructors at the New Brunswick College of Craft and Design, specifically Rachel MacGillivray and Melanie Mitchell, for introducing me to the techniques I am so passionate about. Finally, a big thanks to my parents and sister for their unwavering support throughout all my years of post-secondary education - I could not have done it without you. 


\section{Table of Contents}

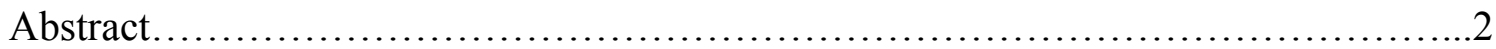

Acknowledgements......................................................2

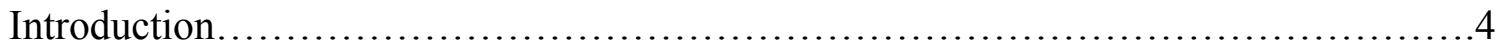

Theoretical Framework..........................................................

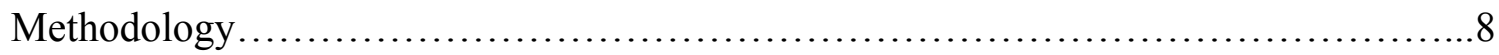

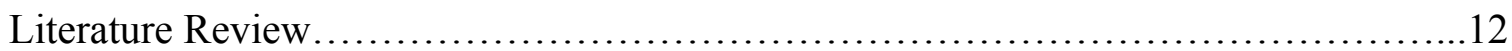

Interpretation of Artworks................................................. 17

Gallery Considerations...................................................... 31

Conclusions \& Future Directions............................................ 32

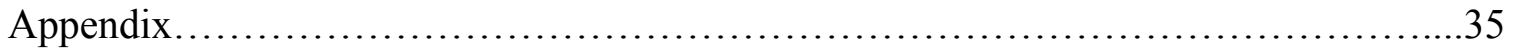

Bibliography.......................................................... 37 


\section{Introduction}

Since ancient times, shibori dyed textiles have been an important part of Japan's visual culture. The opening up of Japanese ports to Western trade in 1853 meant that this traditional textile craft gained international exposure (Wada, Kellogg Rice \& Barton 2011:12). In the seminal text Shibori: The Inventive Art of Japanese Shaped Resist Dyeing, shibori is simply defined as "the Japanese word for a variety of ways of embellishing textiles by shaping cloth and securing it before dyeing" (Wada, Kellogg Rice \& Barton 2011:7). Based on this definition, it is apparent that shibori is an umbrella term - one that encompasses a diversity of processes and many different results. In the 1960s and 70s, many Westerners became acquainted with adapted shibori dyeing techniques in the form of tie-dyed garments - multi-coloured clothing worn by the era's 'hippies'. Youth of the time partook in "a countercultural movement that rejected the mores of mainstream American life" (Encyclopaedia Britannica 2015:n.p.). Today, shibori inspired surface design techniques have once again experienced a resurgence in fine craft schools. According to Glenn Adamson, quoted by Andrea Peach “... craft seems positively fashionable in the present moment, as artists, architects and designers evince a fascination with process and materials not seen since the heyday of the Counterculture in the late 1960s" (Peach 2013:n.p.). Peach writes that revivals in craft have historically been linked to political, cultural and economic shifts.

What is it about these ancient techniques that so appeal to the modern craft practitioner? Is today's technologically advanced world causing people to yearn for the traditional, slow to master oeuvre that shibori symbolizes? In this practice-led research, I argue that shibori's relevance in today's globalized world can be partially attributed to 
increased social and environmental awareness, and partly attributed to consumer habits. Colin Cambell writes that modern consumers see the purchase of craft as a means of selfexpression, just as craft makers do - therefore, the exchange is representative of shared values. Thus, Modern Shibori is intended as an exploration of the potential contemporary applications of shibori techniques through the creation of visual artifacts. This project also engages thematically with the politics of transnationalism, specifically the implications of interpreting the resulting shibori-based artifacts as hybrid cultural products (Coskuner-Balli \& Ertimur 2016:n.p.).

Consequently, this practice-lead research examines the following question: What is the relevance of shibori techniques in contemporary textile design? Textile design, in the context of this project, will be defined as "producing patterns for cloth used in clothing, household textiles (such as towels) and decorative textiles such as carpets. The field encompasses the actual pattern making as well as supervising part or all of the production process" (Wiley 2017:n.p.). Ultimately, the project culminates in a gallery show intended to increase audience appreciation of shibori and its contemporary significance. Additionally, the exhibit will serve to engage audiences outside of the field of academics. Through the project's realization, environmental, thematic, and expressive implications of shibori are explored in relation to textile artworks. Modern Shibori consists of two primary areas of research: shibori and sustainability, and contemporary, innovative application of hand-dye methods.

\section{Theoretical framework}

This research frames contemporary shibori as a hybrid cultural product, meaning a product that is the result of the coming together of two distinct cultures. Arjun 
Appadurai writes that “[i]n today's global consumptionscape, cultural practices are constituted by multidirectional flows of people, technology, financial capital, mediated images, and ideas" (1990:295). This means that not only are these hybrid cultural products a result of our highly connected world, but that they are in fact an important component of our once seemingly disparate cultural identities. This process of hybridization is made up of two key processes - deterritorialization and reterritorialization (Coskuner-Balli \& Ertimur 2016:n.p.). Here, deterritorialization describes the process through which a cultural product or practice is removed from its original context, while reterritorialization is the process through which this product or practice is recontextualized in its new locale. While these processes may seem reminiscent of the problematic concept of cultural appropriation, I will argue, like Coskuner-Balli \& Ertimur, that de- and reterritorialization produces artifacts that are new and legitimate.

This framework is particularly relevant with regards to Modern Shibori. I am Canadian, and having never travelled to Japan, I have relied on secondary sources in order to inform my textile arts practice (deterritorialization). While this body of work certainly pays homage to traditional Japanese shibori, I also intend it to be an exploration of shibori's contemporary surface design applications, transforming it into something original (reterritorialization). Furthermore, for the purpose of this research, I wish to define legitimacy in terms of hybrid cultural products as follows - legitimate works are innovative, non-exploitative and appropriately credit any cultural traditions different from the artist's. These criteria are presented in contrast to typical practices of cultural appropriation, a phenomenon in which members of a 'powerful' culture appropriate 
aspects of one that is 'weaker' for their enjoyment or profit (Carrier 2009:213). The goal of this project is to create pieces that are original, contextually appropriate in the current contemporary fiber art landscape and that clearly reference the techniques' origins.

The above is also consistent with Yazicioglu's definition of reterritorialization in a musical context as "an appropriation process, a cultural pattern that is taken from its social context and applied to a new one in a different physical space, whereas reterritorialization denotes the making of this cultural pattern one's own by producing a local form in this new society and geography" (2010: 240). Different forms of resist dyeing have existed in societies around the world for many centuries, of which Japanese shibori dyeing is only one example. By examining contemporary shibori techniques and artworks as hybrid cultural products, deeper meaning can be gleaned. Additionally, Scott Lash and Celia Lury argue that the current 'culture of circulation' means that "cultural entities take on a dynamic of their own; in this movement, value is added" (2007:5). The aforementioned signifies that not only do the effects of removing a cultural artifact from its original territory and placing it elsewhere have impact on the artifact, but that moving process itself also imbues them with new meaning.

When referring to my work or the work of other practitioners as 'craft', I will do so in following with the discussion outlined by craft scholar Colin Campbell:

The verb to craft means to 'make or fashion with skill, especially by hand' (Hanks, 1979), while the kind of activities that have commonly been regarded as warranting the label 'craft' would include weaving, handblock printing, embroidery, silversmithing, jewellery working, bookbinding, furniture making, and so on. Tanya Harrod (1995) defines craft as 'made and designed by the same 
person', which is a definition that would seem to fit the activities listed above, although she adds that this definition also applies to the fine arts, such as painting or sculpture, such that the boundary between these two spheres is hard to identify. The crucial feature of this definition, however, is the emphasis placed on the fact that the craft producer is someone who exercises personal control over all the processes involved in the manufacture of the good in question (Campbell 2005:27).

\section{Methodology}

Modern Shibori is grounded in practice-lead research, as scholarly research focused exclusively on shibori is lacking - save for a few key texts, primarily the work of Yoshiko I. Wada. Within this body of work I will both refer to, and describe my own work as, contemporary shibori. I define contemporary shibori as textile art that incorporates elements of traditional shibori, but is somehow innovative in terms of technique or media. The 'practice component' involves implementing my existing knowledge of shibori techniques to create artifacts for display in a gallery setting. In terms of method, I employ various textile manipulation techniques related to shibori, such as fold and clamp dyeing, pole wrapping, dyeing with resists and the identification and implementation of natural dye methods. In addition, the research is informed by primary and secondary sources in order to provide both historical and contemporary context and relevance to the creative work that has been produced.

This research is also informed by my participation in the $10^{\text {th }}$ International Shibori Symposium, which took place in Oaxaca, Mexico in November of 2016. I was able to attend a number of panels relevant to my MRP on topics ranging from resist dyeing to 
indigenous textile traditions. In addition, I presented an earlier iteration of Modern Shibori: Beyond Handcrafted Tradition. The experience was extremely valuable in establishing an understanding of the state of the field, and in meeting internationally recognized practitioners such as shibori scholar Yoshiko I. Wada and couturier Deborah Milner. Their feedback, and mastery of their respective fields, encouraged me to push my work to the next level creatively.

I employ a number of techniques throughout the finished works that I will refer to as shibori-based techniques, meaning that they are derivative of traditional methods but do not strictly adhere to their original techniques or materials. I examine not only the finished pieces, but also the process involved in their making to fully articulate their meaning. The decision to undertake a practice-lead research makes sense for Modern Shibori because this mode of research has the potential to create relevant conceptual knowledge, if the process is reflexive (Splitter \& Seidl 2011:114). In order to create a record of the process, I have documented all work photographically and in a creative process journal. This process is consistent with Jennifer A. Moon's description of experiential and reflexive learning, a self-initiated process in which the learner engages through firsthand interaction with the subject matter, then reflects on the process and outcomes, often through "learning journals" (Moon 2013:vii).

For this project, I chose to work with in part with organic cotton and natural indigo, both sourced from Maiwa Handprints Ltd., based in Vancouver, British Columbia. Using organic cotton was an important decision in reducing the environmental impact of the project. In order to maintain water and soil quality, "GMO seeds (genetically modified organism), synthetic fertilizers, herbicides, insecticides, pesticides, 
and toxic chemicals are never used in organic cotton production" (Tutak \& Korkmaz 2012:n.p.). The decision to use natural indigo was also an intentional one. According to a Maiwa publication on indigo and woad dyeing, natural indigo is more expensive to manufacture and can produce uneven results (Maiwa Handprints Ltd.:2016). Despite those potential drawbacks, a study published in The Journal of Plant Science Research states that the use of synthetic indigo "has become a serious cause of environment pollution". Furthermore, natural indigo "was associated with political power and religious ritual and held a significant place in world civilizations for thousands of years", and is often used in traditional shibori dyeing (Sarangi et al. 2011:n.p.).

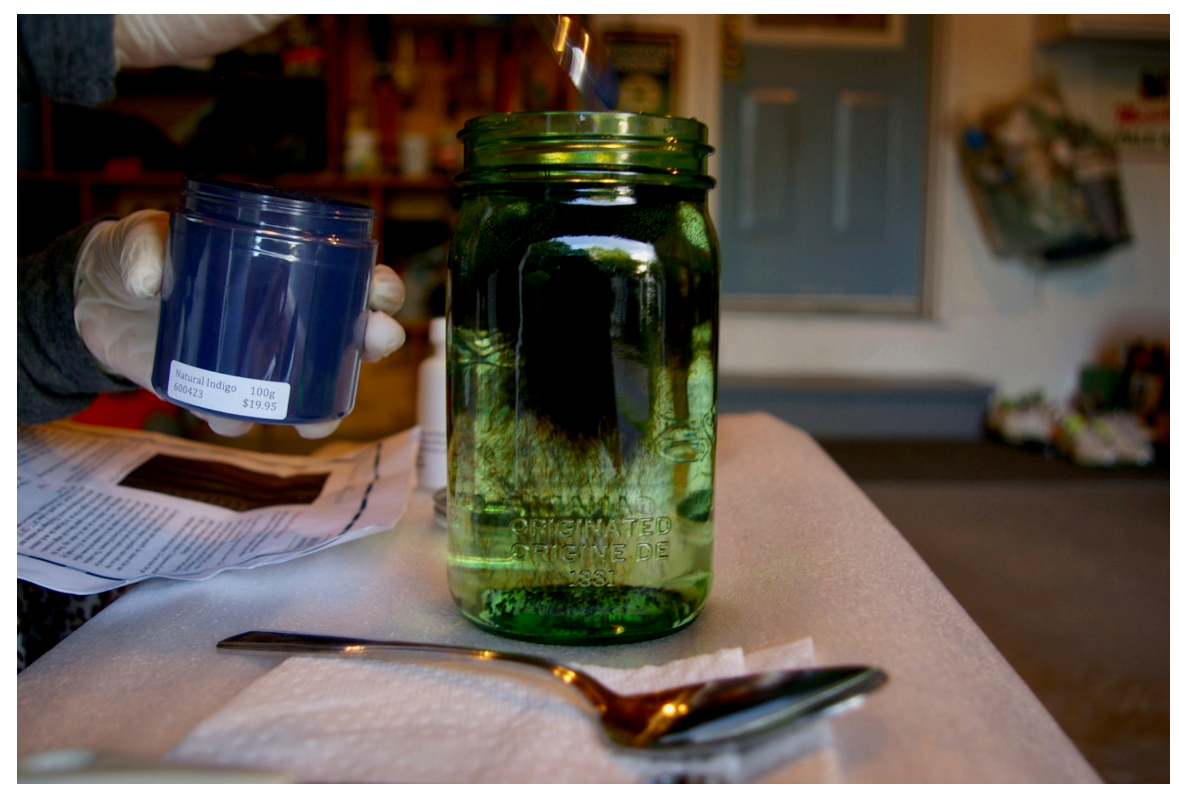

Figure 1: Adding powdered natural indigo to the dye stock solution. Photo by Erin MacQuarrie.

Indigo is extracted from the Indigofera tinctoria, a plant that was traditionally grown in India and Asia (Sarangi et al. 2011:n.p.). Small scale dyeing can be done in a small, contained vat. I started my own dyeing by mixing a dye stock solution of lye, used to produce a basic water $\mathrm{pH}$ level, natural powdered indigo, and thiourea dioxide to deoxygenate the solution (fig. 1, above). After allowing the dye stock to sit overnight, I 
prepared a small vat in the surface design studio at the New Brunswick College of Craft and Design (NBCCD). Deoxygenating the vat produces a green coloured solution, which is an indication that the vat is ready for use. Cloth introduced to the vat turns green, then to indigo's characteristic blue when exposed to the air (fig. 2, below). Multiple dips in the vat produce a darker saturation of colour. When I was first learning to hand-dye cloth, much emphasis was placed on sampling and recording procedures, with the intent of being able to replicate outcomes. For this project, I decided to take a more intuitive approach and simply dye my yardage according to look and feel of the cloth. This serves to further emphasize the inherent unpredictability of both shibori techniques themselves and of natural dyeing with indigo.

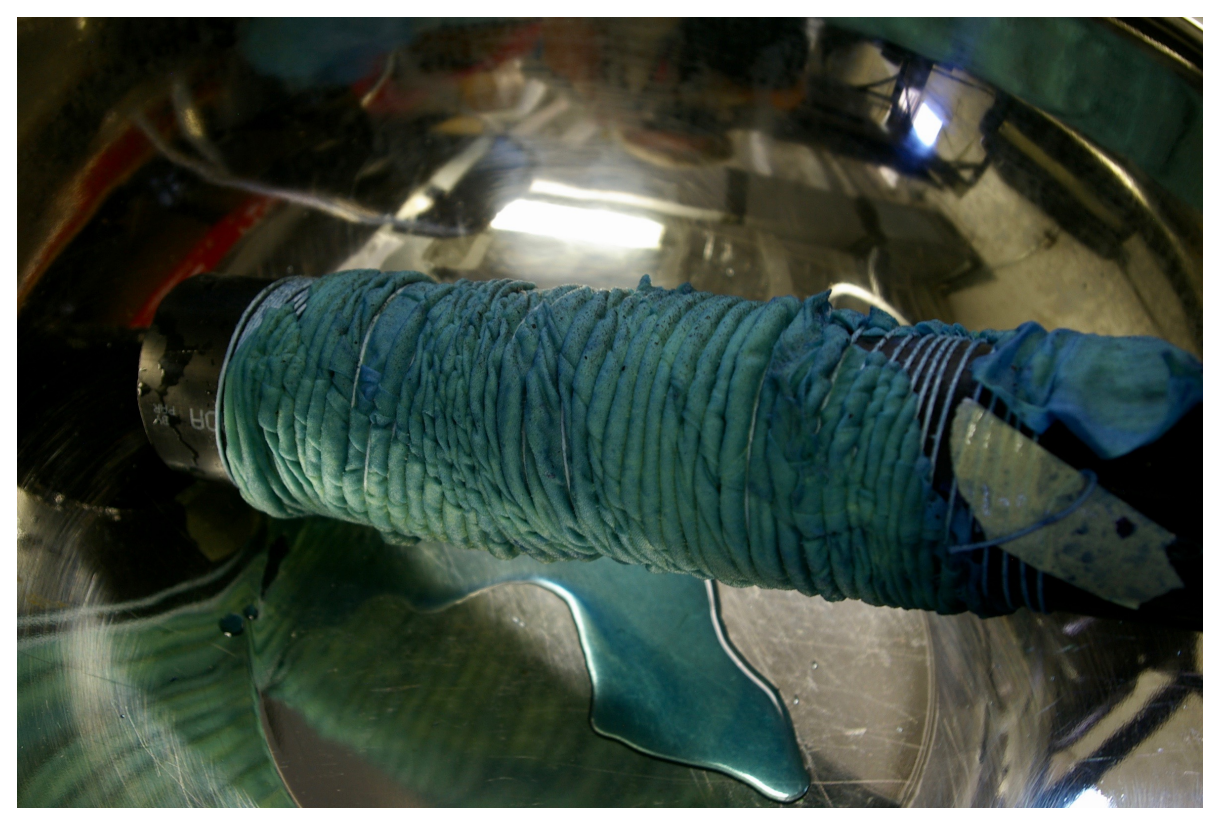

Figure 2: A successfully deoxygenated indigo vat will produce green fabric that turns blue when exposed to the air. Photo by Erin MacQuarrie.

Another important material used as part of Modern Shibori is Canadian wool. Wool is an accessible, local natural fibre and beyond its easy workability, it also symbolizes the resulting pieces' relevance in its new locality. Wool is a sustainable, biodegradable resource and purchasing from local, New Brunswick fibre producers helps 
to support small-scale agriculture (Chitrakorn 2014:n.p.). Purchasing undyed wool and mohair from local suppliers also reduced the overall carbon footprint of the pieces, as these materials do not require extensive processing or shipping.

The main avenue for the dissemination of the creative outcome of this research was a gallery show that took place at Black Cat Artspace in April of 2017. This public exhibition fits into the overall research design, as it allows individuals outside of the world of academics to engage with shibori-based artworks. The audience included people in my various social and professional circles, as well as passersby. The written component of Modern Shibori is principally aimed at academic audiences who wish to connect with more nuanced interpretations of each of the artworks. The research included in this MRP is interpretive, meaning that it is based upon my own perceptions of the works of art both as the maker and as a viewer. A visually appealing gallery show has undoubtedly encouraged others to engage in their own interpretive processes related to the artworks. Facebook has also been a key avenue for dissemination used throughout the research. A dedicated Facebook page allowed me to create an interactive online community around the project (@modernshiboriproject) that interested individuals could subscribe to by 'liking'. Using this forum, I shared behind-the-scenes type content with the project's followers.

\section{Literature Review: Contemporary Fibre Art}

To qualify for inclusion in this MRP's literature review, the works described below have provided insight into the state of shibori itself as a sub-discipline of fibre art, or of fibre art more generally. The objective was to situate my own work within these fields by broadening my understanding of the work that has come before mine. No work 
is created in a vacuum, therefore identifying and acknowledging the accomplishments of others is essential. I sought to find sources that would guide me in considering the physical construction of the pieces, contextualizing historical developments in shibori, and in understanding overarching themes explored by other textile artists.

Wada, Yoshiko Iwamoto, Mary Kellogg Rice, and Jane Barton. Shibori: The Inventive Art of Japanese Resist Dyeing. New York: Kodansha USA, 2011. Print. In this seminal text, the authors give an in-depth overview of shibori-related history and techniques. The first two chapters contain the most authoritative and comprehensive historical account of the technique that I have encountered. While authors acknowledge resist dye techniques from around the world, this work focuses solely on the Japanese tradition. The middle section is devoted to technique, with thorough written explanation, photos, and illustrations corresponding to each variation. This work has largely informed my MRP, both theoretically and in practice, as many of the dyeing methods I used were adapted from these traditional techniques.

Wada, Yoshiko Iwamoto. Memory on Cloth. 1st ed. Vol. 2. New York: Kodansha USA, 2012. Print.

The creative component of this MRP is heavily influenced by the contemporary shibori applications explored in Wada's book. The work explores current artistic practices that are based in shibori techniques. These practices include soft sculpture, textile art and wearables. Wada's book is extremely relevant to my project, as it contains examples of the kind of innovative shibori-inspired pieces that my MRP pieces would be in harmony with. The author acknowledges that in order to keep shibori traditions alive, 
practitioners should be encouraged to innovate. The desire to innovate, and to create successful examples of cultural hybridity, was one that largely informed my MRP work. Monem, Nadine Käthe. Contemporary Textiles: The Fabric of Fine Art. London: Black Dog Pub., 2008. Print.

This source covers a wide variety of textile art and design topics, but focuses mainly on what the title implies: making the case for textile art as fine art. Traditionally, textiles were primarily meant to be functional, and were the responsibility of women. The author argues that contemporary textile art has come to transcend the perceived boundary between art and craft, and low and high art. My intention with Modern Shibori is to continue this dialogue. The author also explores the relationship between textiles and the body and themes of corporeality. Textiles appeal to the senses, and are also worn directly on the body, giving them an emotional and physical closeness to a person. This relationship between people and clothing discussed in this text was influential in my decision to incorporate a garment into the MRP exhibition.

Ullrich, Polly. Material Difference: Soft Sculpture and Wall Works. Seattle: U of Washington, 2007. Print.

This book is primarily a visual catalogue containing color photographs of works from a number of contemporary textile artists. In the glossary, the author offers some brief definitions of textile decoration methods, including shibori. They write "[t]his is extensively practiced in Japan and was very popular in the 1960s as tie-dye" (17). The reading lists a number of traditional textile manipulation techniques that continue to be used in modern-day work, such as quilting, embroidery and knitting, in addition to new, more unique materials such as fish skin and melon peel that have been stitched together. 
The book is divided into two main sections: gallery work and work situated in the home. The former is more relevant to my MRP, as I intend to further justify textile art's relevance as not only craft but also as fine art. This reading was primarily informative as an overview of the state of contemporary fibre art.

Hemmings, Jessica. The Textile Reader. New York: Berg, 2012. Print.

This work is comprised of a great number of articles written by scholars in the fields of fashion, art and textiles. The relationship between textiles and the senses is explored in depth. A key theme is the relationship between textiles and memory. Textiles play a vital role in peoples' everyday lives in the form of clothing, upholstery, and decoration, and are therefore an understandable part of memory formation. The editor has also included the concept of traditional creation versus the more modern trend of upcycling - taking existing materials and combining and repurposing them to create new meaning. This MRP contains both more traditional textile creations and upcycled works, as I believe that both are extremely valuable to the audience's holistic understanding of the project's values, including sustainability.

Porter, Jenelle. Fibre Sculpture: 1960-Present. New York: Prestel, 2014. Print. This book focuses primarily on three-dimensional, sculptural fibre works. The author defines fibre art as emerging in the 1960s and 70s. Again, this reading traces the path of textiles from a functional commodity to fine art "amenable to monumental scale". It profiles a number of influential fibre artists including Magdalena Abakanowicz, who define their work by playing with scale. The topic of installation, creating a space for viewers to engage and interact with using their senses, is explored. Many of the works featured in this book seem to embrace dimensionality and ask viewers to ponder what it 
means to occupy space in the world. Rather than being functional and utilitarian, the author positions contemporary textile art as being abstractive, conceptual and often nonrepresentational. This work provides a historical background for textiles as fine arts and was influential in my decision-making with regards to installation of the MRP's pieces - highlighting their three-dimensionality.

Rose, Barbara. Magdalena Abakanowicz. New York: Harry N. Abrams, 1994. Print.

This reading chronicles the life and work of Magdalena Abakanowicz, a prominent sculptor and textile artist. Born in Poland, her early work was limited by the Soviet Union's preferred style, called "Socialist realism”. Abakanowicz is perhaps most well known for her large scale, humanoid sculptures called Abakans. Another series is called War Games, and is made up of large discarded tree trunks fitted with metal hardware. Her work incorporates themes of war, corporeality, and subverted gender roles. Abakanowicz also seems to challenge the common perception of cloth - that it is soft and delicate. Her burlap and rope sculptures are sturdy, rough and monumental. Her installation pieces invite viewers to enter the world of the uncanny. While my work has little in common with Abakanowicz's upon first glance, I believe that this work was essential in situating this MRP within the larger scope of contemporary textile art as a discipline.

Prain, Leanne. Strange Material: Storytelling Through Textiles. Vancouver: Arsenal Pulp, 2014. Print.

Part textbook and part instructional guide, this reading explores textiles as a narrative device. The author encourages artists to "find their voice" and to thoughtfully 
convey their intended message through fibre art. Cloths' link to memory is also examined, and is positioned as an effective aid in storytelling. Textiles, and their link to tradition, are questioned and reimagined to make a political statement about gender, art and society. Many of the pieces featured in the book contain written language applied to the cloth using different media. This is a very literal means of communication - one that uses text to spell out what the artist wishes to say. While writing and poetry is not particularly relevant to my MRP, effective communication certainly is. My goal was to create textile works that were able to communicate key concepts effectively through visual elements such as texture, colour, and shape.

Conducting a literature review has been critical in my understanding of traditional shibori history and techniques - the basis of what I have built this MRP around. Understanding how my work my work is similar to, and divergent from, both shibori and contemporary forms of fibre art have helped me to situate the work in time and space. Consistent with many other practitioners of textile art, my goal for this MRP's works is to bridge the perceived gap between craft and fine art. I do not think that they should be mutually exclusive disciplines, or that one is more inherently valuable than the other.

\section{Interpretation of Artworks}

I considered a number of criteria both while completing practice component of this MRP, and subsequently in curating the finished pieces for exhibition. I will refer to these as the works' criteria for inclusion, and they are as follows. The primary criterion for inclusion in the exhibition was that all works must incorporate some aspect of shibori, whether that is the explicit use of a traditional shibori technique or a looser visual metaphor. Perhaps most importantly, the works must be thematically consistent with the 
theoretical framework outlined above - that of the hybrid cultural product. This means that they must be globally inspired, but grounded in the contemporary cultural context in which I am working. They must also incorporate craft techniques, specifically those referential to techniques used in traditional textile art. The final criterion was that all works must have minimal environmental impact, and therefore be primarily made up of sustainable materials, dye, and finishings.

Conceptually, the works of art themselves are very much informed by remix culture - a concept that revels in hybridization and "derivative works". Remix culture can be simply defined as one which members partake in "combining or editing existing material to produce a new product" (Duncum 2013:10). Many of the pieces created as part of this MRP are derivative of other fibre art traditions, but their intention is to illustrate something greater than the sum of their parts. The works are detailed below by title. 
Shibori Basics

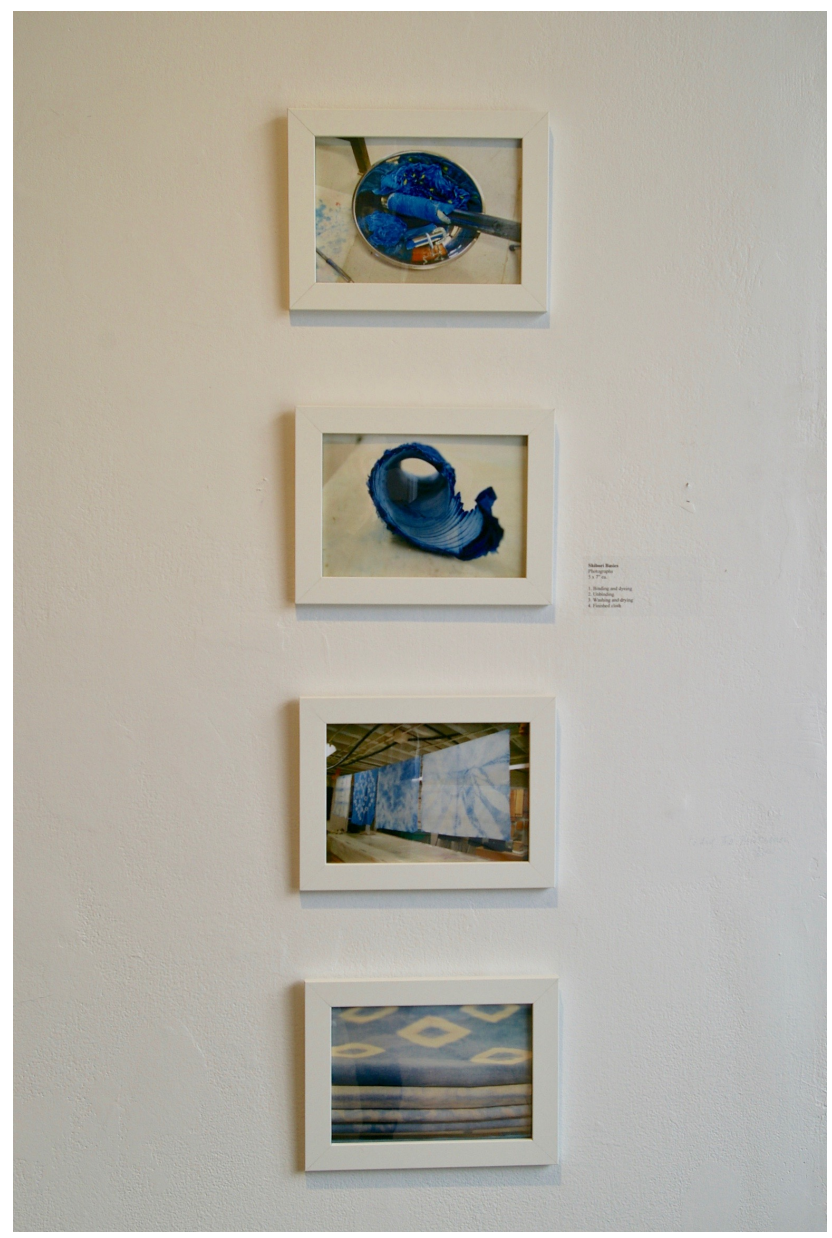

Figure 3: Shibori Basics. Photographs. 5 x 7" ea. Photo by Erin MacQuarrie.

Firstly, when entering the exhibition, viewers are introduced to the works of art by a series of four photographs (figure 3 , above). These photos are intended as a visual legend - one that guides viewers though the basic steps of shibori dyeing. For those unfamiliar with shibori, this piece offers an opportunity to visualize the process that inspired all of this MRP's works, even if it was applied to the piece in an indirect manner. The four photos represent the following shibori making steps: binding and dyeing, unbinding, washing and drying, and finished cloth. All photos were taken at the New Brunswick College of Craft and Design while I was working with a natural indigo vat in their surface design studio in August of 2016. 
Depicted in the 'binding and dyeing' photograph are bundles of resist-bound cloth after being submerged in the indigo vat. The following, 'unbinding', shows the tubular piece of arashi-bound cotton from the first image, which maintains its shape even after the center tube and outer twine have been removed. The subsequent photographs depict the cloth after it has been washed and has recovered its two-dimensionality. These photographs have been carefully selected to provide the audience with a foothold in their exploration of the exhibition. Viewers are therefore able to draw links between the basics of shibori dyeing and any visual allusions made in the subsequent artworks.

Reverence Panels

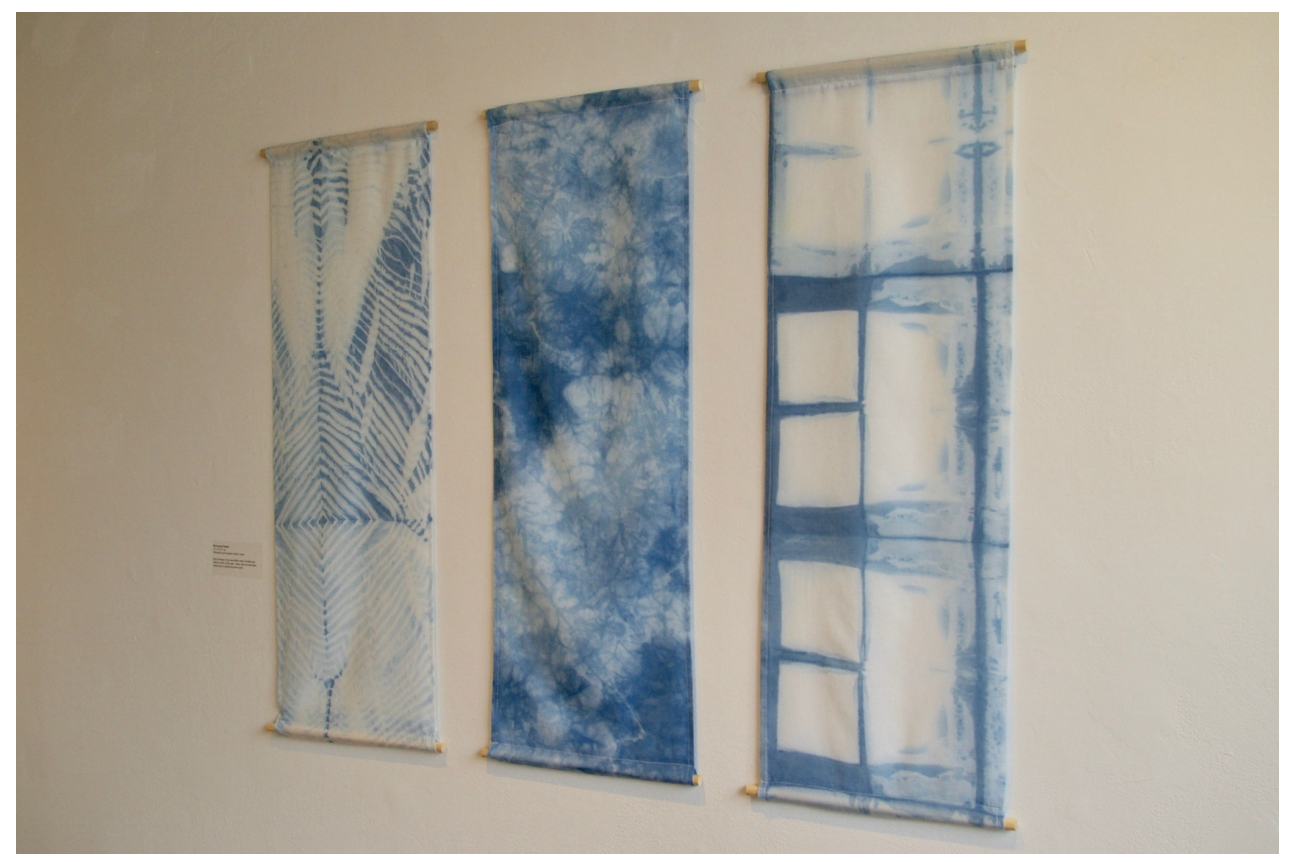

Figure 4: Reverence panels. 11 x 32.75" each. Naturally dyed organic cotton, wood. Photo by Erin MacQuarrie.

These panels (figure 4, above) are perhaps the most traditional example of shibori dyeing included in the exhibition. Drawing on techniques outlined in Wada et al.'s The Inventive Art of Japanese Resist Dyeing, these pieces are intended to engage with viewers unfamiliar with shibori dyeing and to act as an introduction to a small sample of the 
various visual possibilities of the technique. The panels are made of organic cotton sourced from Maiwa Handprints, a textile store and learning center based in Vancouver, British Colombia. The cotton is from India and has been lightened with a natural whitening process using banana fibre potash (Maiwa 2017:n.p.). I washed and dried the cotton yardage before dyeing it in a natural indigo vat, explained in greater detail in the Methodology section of this document. The resists were applied in such a way to produce three different shibori patterns: arashi, meaning "storm" for its irregular rainfall-like pattern, itajime, which is the name for folding and clamping the fabric between two blocks of wood, and a loose crumple pattern (Wada, Kellogg Rice \& Barton 2011:n.p.). The pieces were cut and sewn to equal size and suspended between from 12-inch wooden dowels. These panels are visually reminiscent of Japanese scroll paintings and therefore connect with the cultural origin of shibori.

I have titled these collective works the Reverence Panels, because they are intended to pay homage to the incredible work of traditional shibori artists of the past those who devoted their entire lives to perfecting their craft. Ultimately, I would like for viewers to come away from this piece with not only a greater appreciation of traditionalbased dyeing techniques, but also an open-minded perspective on the possibilities that shibori dyed cloth possesses for contemporary surface and textile designers.

\section{Reterritorialization I \& II}

These two pieces were titled as such because they exemplify Coskuner-Balli \& Ertimur's concept of de- and reterritorialization, explored in the Theoretical Framework section of this project. Both are primarily made of sheep's wool - a sustainable material 
that can be successfully grown and processed in Canada, unlike many plant-based fibres such as cotton.

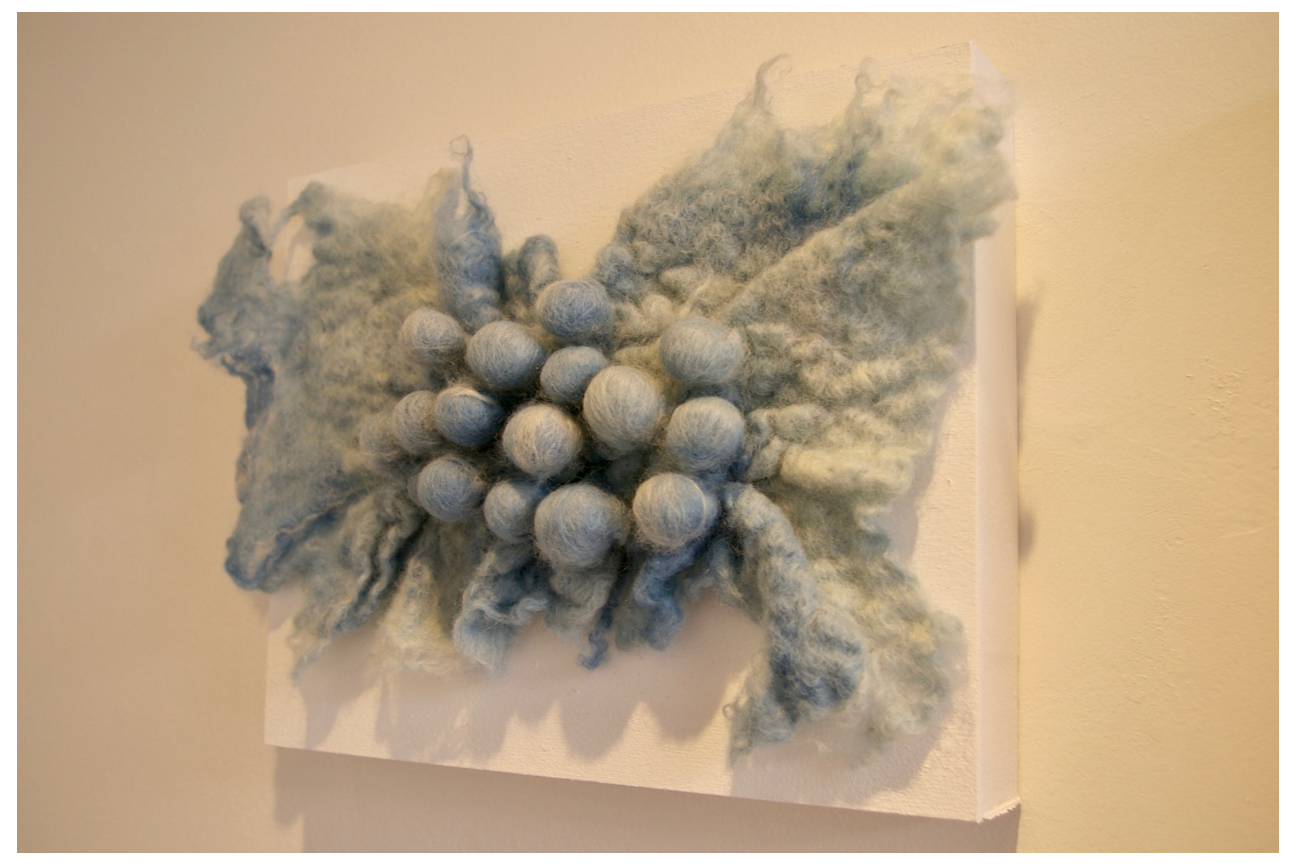

Figure 5: Reterritorialization I. 11 x 7". Naturally dyed wool, mohair. Photo by Erin MacQuarrie.

For Reterritorialization I (figure 5, above), I used wool roving, a bundle of fibre that has been carded, naturally dyed with indigo purchased from Mary LeRoy of Pine Spirit Woolworks. The roving is made from USA domestic Bluefaced Leister (BFL) sheep's wool. I felted the wool using a method called wet felting, which was introduced to me at the New Brunswick College of Craft and design. Many wool blends are available on the market today, which combine natural wool with synthetics such as acrylic. One of the reasons for blending fibres is for easy care and laundering on the part of the consumer, as acrylic will not mat or felt in the same way as wool. Felting is itself an ancient technique, one which occurs when wool fibres are exposed to heat and friction, with the tiny scales along the surface of the material essentially hooking together to create a durable cloth without grain. There are also chemical treatments that can be 
applied to wool to reduce its felting properties, with varying degrees of environmental impact (Kantouch et al. 2007:65).

After reaching a soft-felt stage I bound resists, in this case glass marbles, into the cloth and continued to felt until I was satisfied with the cloth's texture and stiffness. After drying, cloth held the shape of the resists even when they were removed. This resulting three-dimensional cloth is visually interesting and retains the essence of the shibori resist process even in its finished state. In that way, the processes that it has undergone permanently alter it, similar to cloth that has undergone traditional shibori dyeing. The cloth's edges have been left in an irregular state, representing the inherent irregularity of shibori dyeing, but also of fibre art in general. The hand of the maker is made prominently visible in this piece - it could not have been made by machine.

In Reterritorialization II (figure 6, below), I used undyed Canadian wool from Briggs \& Little, a New Brunswick mill based in York Mills. According to their website, Briggs \& Little is "one of the few remaining vertical woolen mills in Canada and North America. For example, our woolen mill performs all of the processes and functions to change raw wool into wool spun yarns and products, all under one roof' (Briggs \& Little Woolen Mills Ltd. nd.:np.). Purchasing yarn from a local producer not only helps to support small, family owned businesses, but it also means that the wool used in this project has a traceable supply chain. Less transportation of raw and finished materials also means that the wool has a lower carbon footprint than material that has been imported from overseas. This concept can be scaled up to include the textile and garment industries as a whole. Writes Tsan-Ming Choi, “[e]mpirical reports and cases all reveal 
the fact that green supply chain management is critical to the sustainability of many industries which include fashion apparel” (2013: 835).

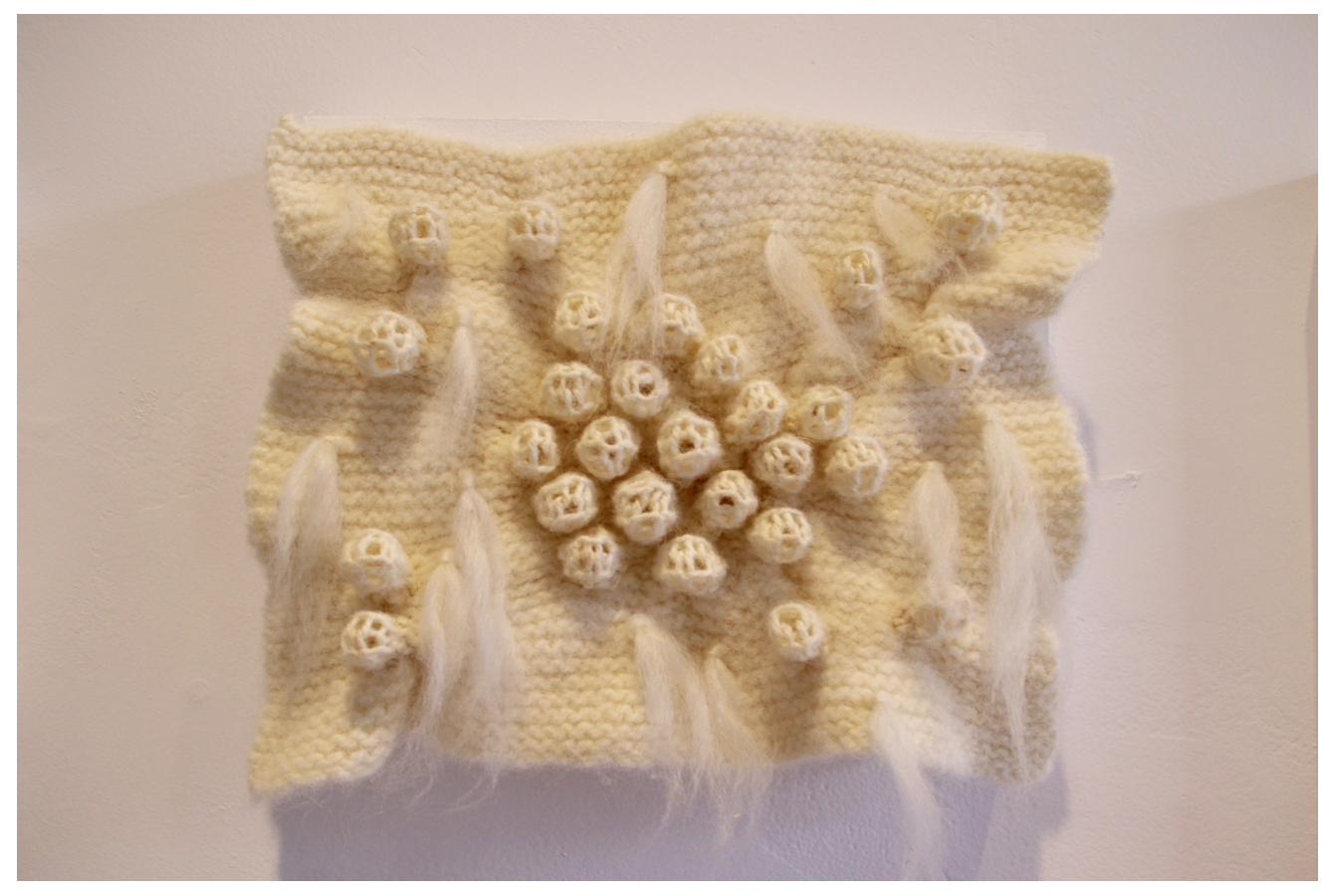

Figure 6: Reterritorialization II. 11 x 9”. Wool, mohair. Photo by Erin MacQuarrie.

The yarn was knit using a basic stockinet stitch on 6 millimeter needles before resists, again glass marbles, were bound in an abstract fashion. The piece was then felted in the same manner as described above. The resulting cloth was not completely without grain like that of Reterritorialization I, it retains some of the original knit texture despite having been felted. The areas in which the resists were bound once again remain visible, but this time the initial knit structure of the cloth creates an almost lattice-like effect in the raised areas. This gives the viewer a sense of the stretched, strained state of the cloth when it was being manipulated. To create contrast between the structured courses and wales still visible in the finished cloth, I added embellishment in the form of tufts of local mohair roving from T Ray Woolies, a farm based just outside of Grand Falls, New Brunswick. Mohair, from Angora goats, has a beautiful soft hand and vibrant luster, 
which distinguishes it from the sheep's wool yarn. It was attached to the cloth by hand using a traditional rug-hooking tool.

As discussed above, these pieces serve to exemplify the concept of deterritorialization and reterritorialization - they incorporate Japanese shibori-based techniques with local, site-specific materials such as wool and mohair. Both pieces are similarly representative of hybrid cultural products, and were created using the same style of resists. For that reason, I have chosen to present them as a set of works rather than as two stand-alone pieces.

A Thing to Wear

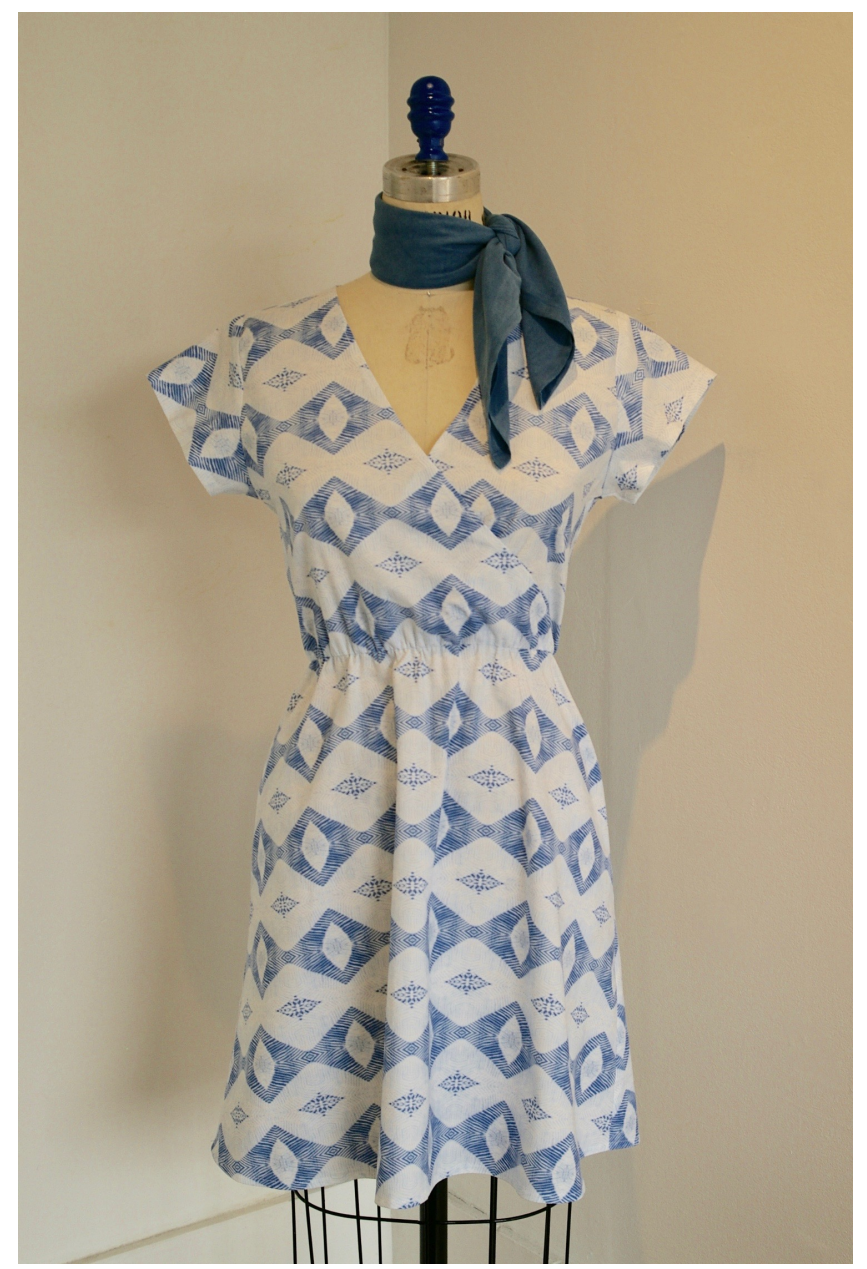

Figure 7: A Thing to Wear. 28" waist, 20.25" length. Digitally printed cotton, elastic tape. Photo by Erin MacQuarrie. 
In considering the inherent unpredictability of shibori as a design technique, I asked myself what I would consider it's opposite. The words that came to mind, as antonyms to 'unpredictable' were predictable, mechanized, consistent, uniform. In many ways, these words represent the antithesis of craft as a whole. Colin Campbell summarizes this dichotomy nicely in his article The Craft Consumer: "[T]he term 'craft' is actually a shortened version of the word 'handicraft', a term that immediately draws attention to the contrast between the traditional worker, who produces objects 'by hand', and the modern factory worker, who produces them with the aid of a machine" (Campbell 2005:28).

The cloth used in this garment was created in such a way as to bring together traditional shibori and contemporary fabric printing technology. First, I dyed organic cotton in a natural indigo bath as described above, using arashi technique. I then cut a small piece of the cloth that I found to be visually interesting and scanned it, turning it into a digital file (figure 8, below). I subsequently uploaded the file to Spoonflower, an on-demand fabric printing company based in North Carolina. According to their website, “Spoonflower's digital print process uses eco-friendly, water-based pigment inks and dyes which produce very little waste. And with over 350,000 designs (plus more added every day), the Spoonflower Marketplace is the largest collection of independent designers in the world" (Spoonflower n.p.:n.d.). The company allows small designers to print textiles of their own design with low order minimums. I chose to tile and mirror the original scan to produce a unique, symmetrical pattern that would be impossible to create through shibori dyeing. The result is a visually interesting cloth that is a hybridization of hand-dyeing and digital textile design. I ordered a relatively small amount of the printed 
cloth, but the design could be scaled up infinitely for commercial applications such as use in the fashion industry.

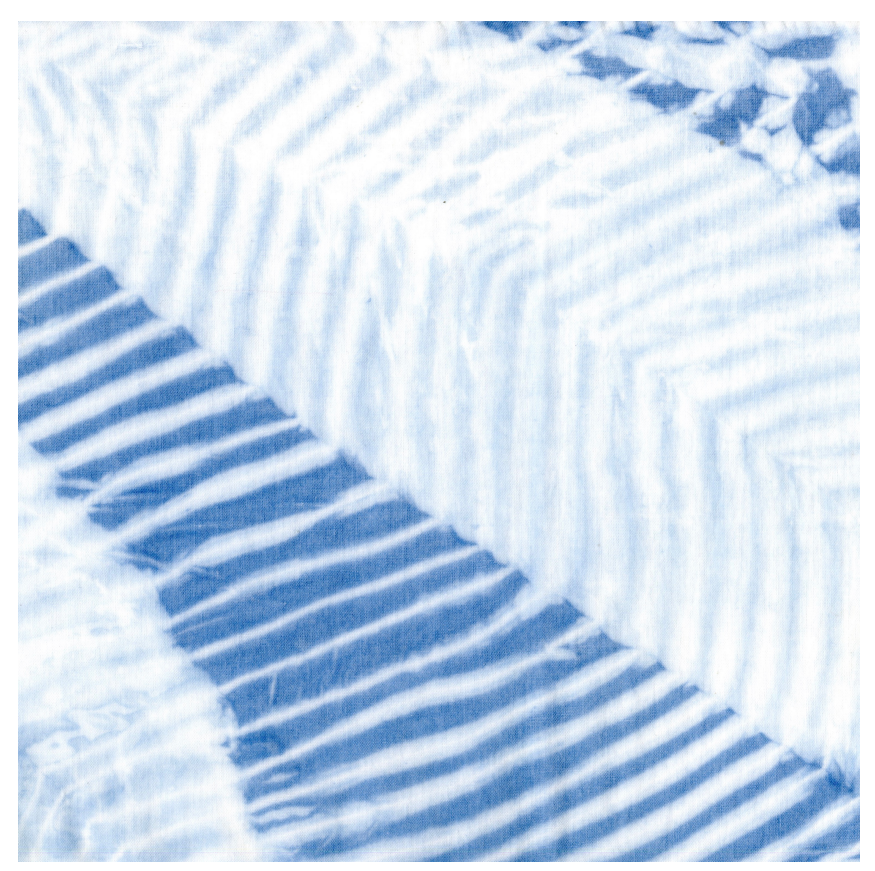

Figure 8: A digital scan of shibori dyed fabric used to create a repeat pattern.

The garment itself was made from a pattern purchased through a website called Craftsy which, similarly to Spoonflower, allows independent designers to upload their own work to sell. I chose to have the dress itself made at a local shop in Toronto, Ontario, instead of sending it internationally. I chose a pattern for a simple wrap-style dress, as a very intricate garment may have distracted from the cloth itself. The overlapping $\mathrm{v}$ neckline is reminiscent of the traditional Japanese kimono, simply meaning "a thing to wear", which is a loose-fitting article that is tied at the waist (Walkup 2015:42). I had a garment made from the digitally printed fabric instead of displaying it as a stand-alone piece, allowing viewers the opportunity to experience the work in a form in which they are familiar - as clothing. All of the textile work produced as a part of this MRP has potential applications outside of the gallery, but this one explicitly so. All viewers, 
despite their backgrounds, interact with clothing on an everyday basis whether they consider themselves interested in fashion or not.

Synergy (Greater Than the Sum of its Parts)

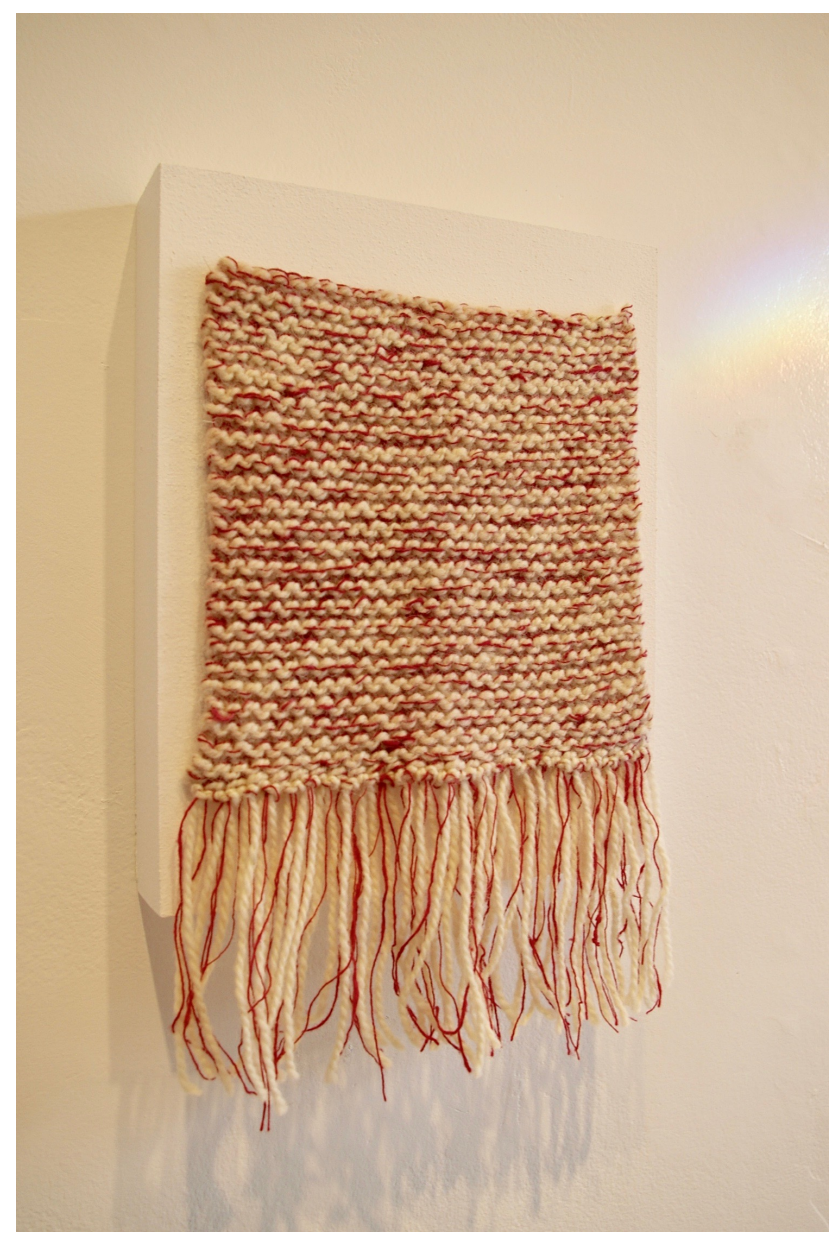

Figure 9: Synergy (Greater Than the Sum of it's Parts). 7.25 x 6.5", 4" fringe. Wool, naturally dyed handspun silk. Photo by Erin MacQuarrie.

This piece (figure 9, above) is a largely literal interpretation of the hybrid cultural product as discussed in the Theoretical Framework section of this document. In November of 2016, I presented an earlier iteration of this project at the $10^{\text {th }}$ International Shibori Symposium (10ISS) in Oaxaca, Mexico. At the conference, I participated in a silk spinning and dyeing workshop with Moises Martinez, a traditional silk weaver from San Pedro Cajonos, Oaxaca. Martinez's family cultivates silk worms, creates fine hand spun 
yarns using a drop spindle made of gourd and clay, dyes them using natural, local dyes, and finally weaves the yarns into cloth. I was able to dye a skein of Martinez's silk yarn in a dyebath of a local form of Brazilwood, mordanted with alum and cream of tartar. The Brazilwood produced a beautiful, vibrant red.

To create Synergy (Greater Than the Sum of its Parts), I loosely plied a length of the Oaxacan silk wool with the same undyed Briggs \& Little wool yarn used in Reterritorialization II. After knitting, the result is a slubby, textured cloth that is beautiful in its simplicity. This physical blending of Oaxacan fibre with Canadian fibre is representative of cultural hybridity and the impact that it has had on this project. My involvement in 10ISS was absolutely critical to advancing my understanding of the state of the field and my own place within it. In order to finish the piece, I added a fringe made of the same textile body materials. The fringe is a nod to Oaxaca's rich fibre art traditions, specifically to the beautiful woven cloth produced by the indigenous people of southern Mexico. The warp fibres of woven cloth are often finished off with a fringe to keep them from unravelling. Since knit cloth possesses a different structure than woven cloth, I affixed the fringe using a rug-hooking tool.

Synergy (Greater Than the Sum of its Parts) is so named because despite its relative simplicity, the piece is very meaningful to the overall project. Synergy is a word of Greek origin defined as "the interaction or cooperation of two or more organizations, substances, or other agents to produce a combined effect greater than the sum of their separate effects" (Merriam-Webster: 2017:n.p.), and I believe that this definition is very relevant to the piece. Synergy is the only work in this MRP in which shibori techniques were not used in its making. However, despite the digression from the above-articulated 
criteria for inclusion, I consider the work thematically consistent and an important addition to the MRP as a whole. The coming together of fibre from two regions that are geographically important to this body of work is both a literal and symbolic synthesis of cultural products to form a hybrid cultural product.

\section{Collage}

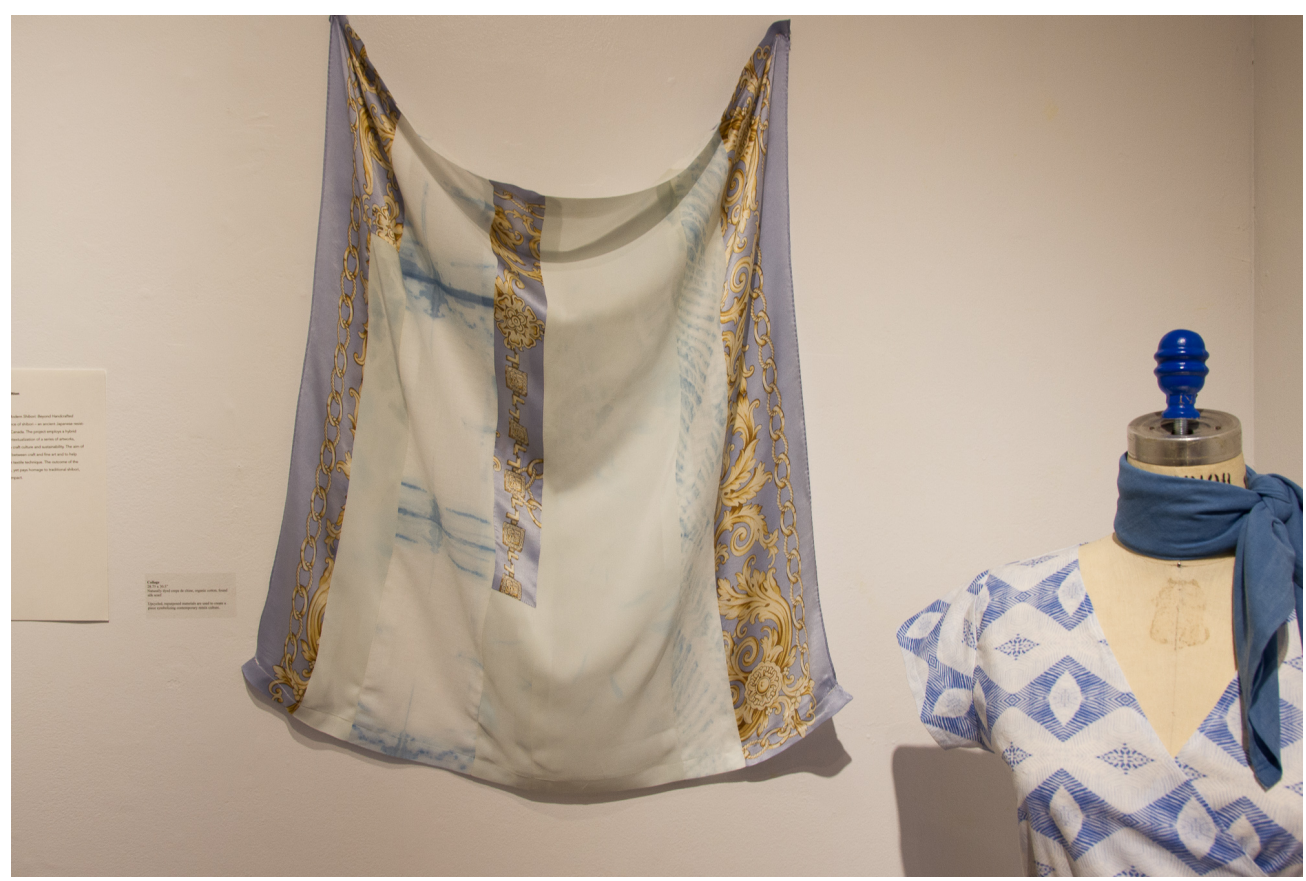

Figure 10: Collage (left). 28.75 x 30.5". Naturally dyed crepe de chine, organic cotton, found silk scarf. Photo by Teagan McCanny.

This work is what I would consider a fibre collage, similar to the cutting and reassembling of photographs that constitutes a traditional collage. In this way, the work is consistent with remix culture - combining and editing existing materials to create a product with new meaning. The piece (figure 10, above) is made up of strips of shibori dyed organic cotton, crepe de chine, and a vintage silk scarf. With this piece, I wish to explore the concept of upcycling, defined by Matthew Wilson as "a form of creative consumption" (Wilson 2016:394). Upcycling occurs when the consumer repurposes their waste instead of throwing it away, as was the case with the initial silk scarf. Wilson also 
writes: "the outcome of upcycling can be deemed a green technology, as it allows consumers to reduce their environmental footprint" (2016:395).

In addition to repurposing the silk scarf, the strips of cotton and crepe de chine were initially scrap material left over in the creation of other pieces for this MRP. The pieces of cloth were assembled in a way that resembles a quilt - a very familiar textile craft for most viewers.

\section{Gallery Considerations}

For this MRP's gallery show component, an essential part of disseminating the work, I decided to partner with a classmate to best use the resources available to us. After thoroughly researching available gallery spaces in the city, we decided to book Black Cat Artspace, a small storefront gallery located in Toronto's west end. In addition to sending electronic and paper invitations to our respective personal and professional networks, the gallery's large front window allowed for passersby to engage with the project - once again broadening its potential impact. For Black Cat Artspace's floor plan, see Appendix ii. I chose to frame and mount the artworks in a minimal fashion so that the focus would remain on them and not the hardware. With the exception of Replicability, textile works were not displayed behind glass so that the viewer could best appreciate the their texture and dimensionality. Instead, smaller pieces were mounted on raised wooden panels painted white with interior acrylic paint, harmonious with the gallery's walls, intend to give the impression that the pieces were floating. A Thing to Wear, the show's only garment, was displayed on a dress form to give viewers a greater sense of corporeality that may have been lost if it was shown flat. Overall, the exhibition's design was intended 
to guide the viewer through various shibori-based techniques in a coherent, easy-tofollow fashion, allowing them to focus on the works' themes.

\section{Conclusions \& Future Directions}

My journey through Modern Shibori: Beyond Handcrafted Tradition has been one of immense learning and personal growth. Most importantly, however, my aims for this project was not only for me to put into practice my own skills and knowledge, but also to share discourses about textile culture, textile design and fashion as a whole with a larger audience. While 'sustainability' has become somewhat of a trend as of late, with massmarket retailers quick to label their products as adhering to the concept, I believe that it should be treated as a lifestyle rather than as a fad. Thus, one of my main objectives with regards to this project was to engage viewers through visually interesting fibre artworks and prompt them to consider the environmental impacts of textile consumption, as well as some possible alternatives. All people engage with textiles daily in some form or another, whether it is through clothing, home furnishings or any other common application. I would argue, however, that the average consumer rarely stops to consider how those textiles were made or what they were made from.

This disconnection between people and cloth is a factor in why craft in general, and shibori in particular, remain relevant in today's technology-centric world. According to Colin Campbell, consumers purchase craft as a way to express themselves (Campbell 2005:23). This could be interpreted to mean that the values that craft represents - for example sustainability, small-scale production, and supporting local economies resonate with contemporary consumers at an individual level. Leading shibori artist and scholar Yoshiko I. Wada supports these suppositions. When asked for her opinion on 
why young people are attracted to the technique, she writes via email: "Probably

awareness to sustainability issues in environment and our cultural traditions. Also, some are jaded by technological development in our society. Shibori is immediate, spontaneous at the same time it can be very challenging and requires discipline" (Wada 2017:n.p.).

The physical artefacts created for this project add to the body of contemporary textile art that exists today. In line with my fellow textile artists, my hope is that by positioning artworks that incorporate craft techniques in a gallery setting, viewers will be more inclined to appreciate them as objects of cultural value. The modified, shibori-based techniques used in the above-described pieces are my way of actualizing an ancient textile tradition, while still respecting its Japanese origins. In our globalized world, hybrid cultural products will continue to exist and evolve, but I believe that it is very important to be knowledgeable and intentional when drawing inspiration from cultural legacies that are not the artists' own, as was the case with Modern Shibori. As evidenced in the interpretation of these pieces, hybrid cultural products possess value greater than the sum of their parts.

While Modern Shibori: Beyond Handcrafted Tradition provides an insight of its own, it also poses many questions that could lead to further research. One such future direction could involve in-depth research into the environmental impact of this and similar projects, with the aim of minimizing the use of non-renewable or unsustainable resources. This may include further analysis of natural dyes and their small- and largescale applications.

Another interesting area for further study that I was unable to pursue within the scope of this MRP is to closely examine the communities of people that surround shibori 
as a technique. For example, what kinds of shared values do people who practice shibori possess? Do particular life experiences, or the possession of certain forms of cultural capital, affect one's interest in shibori or textile arts more generally? The impacts of digitization could also be examined - it seems logical that the advent of the Internet would impact the ways in which knowledge is passed from more established members of such a community to newer members. From a pedagogical perspective, it would be valuable to better understand how the methods involved in teaching shibori impacts the learning of these techniques. In order to ensure the survival of the technique, it is essential that young and upcoming practitioners continue to understand its value. How can this be best accomplished? Ultimately, this complex and interesting topic is one that merits greater exploration, research, and consideration by the academic field of academics. 


\section{Appendix}

i. $\quad$ Pattern information used to create $A$ Thing to Wear, purchased from Craftsy

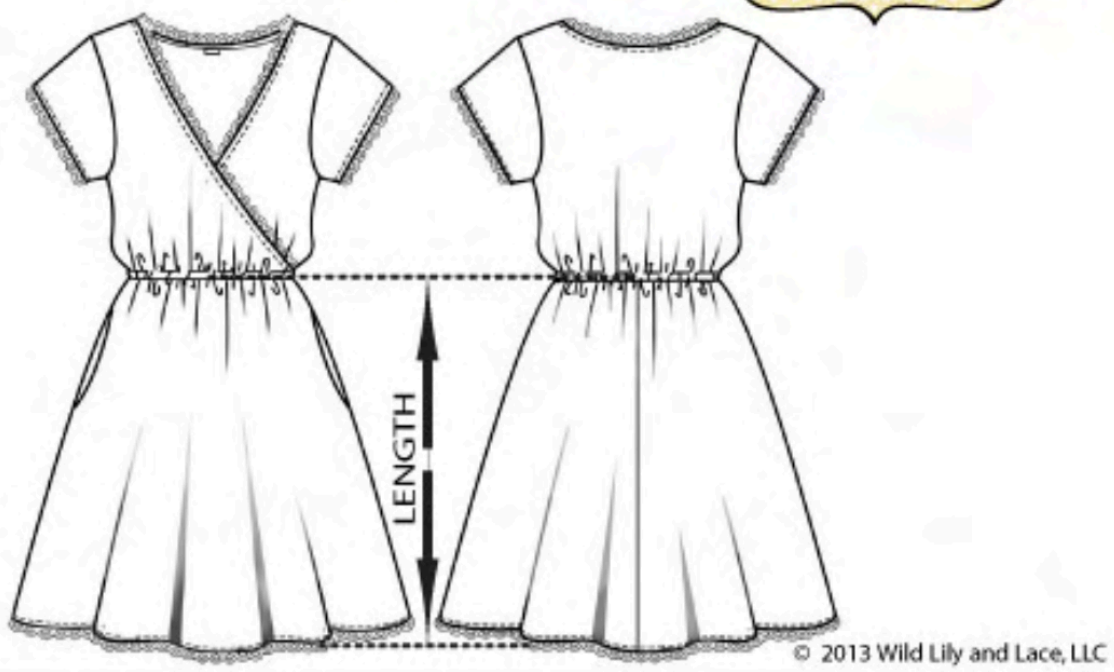

Finish Garment Measurements In Inches

\begin{tabular}{l:l|l:l:l} 
& & ELASTIC & & \\
& BUST & WAIST & HIP & LENGTH \\
\hdashline XSMALL & 34 & $23-24$ & $411 / 2$ & 19 \\
\hline SMALL & 36 & $25-26$ & $431 / 2$ & $191 / 2$ \\
\hline MEDIUM & 39 & $27-29$ & $461 / 2$ & $201 / 4$ \\
\hdashline LARGE & 43 & $30-32$ & $501 / 2$ & $211 / 4$ \\
\hline XLARGE & 47 & $33-35$ & $541 / 2$ & $221 \% 4$ \\
\hline
\end{tabular}

See Pattern for fabric, trim and notions information 
ii. Black Cat Artspace (2186 Dundas Street West) floor plan

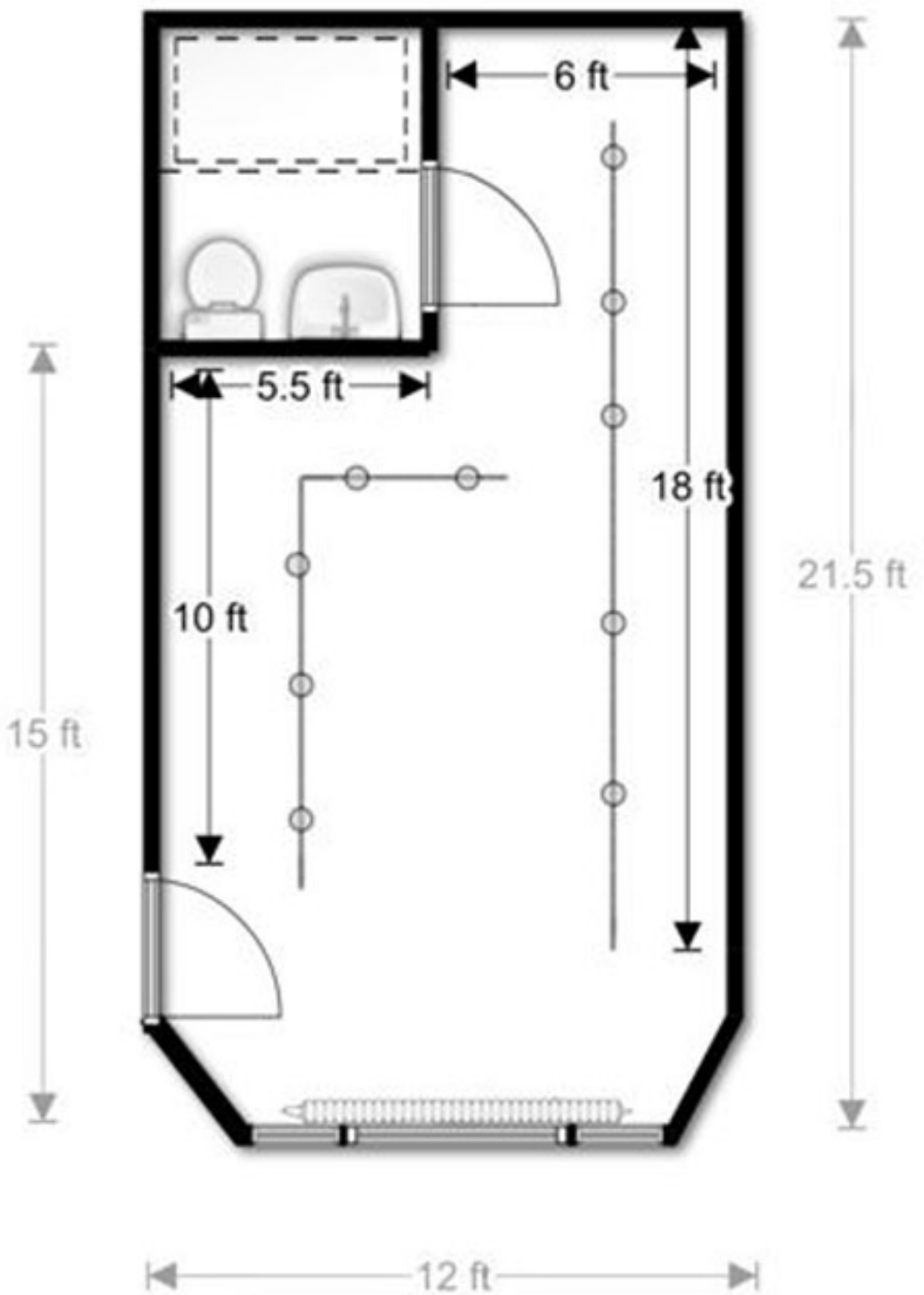




\section{Bibliography}

"All About Us." Spoonflower. N.p., n.d. Web. 13 Mar. 2017.

Appadurai, Arjun. "Disjuncture and Difference in the Global Cultural Economy." Theory, Culture \& Society 7.2 (1990): 295-310. Sage Journals. Web. 5 Jan. 2017.

The Authors of Encyclopaedia Britannica. "Hippie." Encyclopaedia Britannica. Encyclopaedia Britannica, Inc., 02 Sept. 2015. Web. 3 Apr. 2017.

Burman, Barbara, ed. The Culture of Sewing: Gender, Consumption and Home Dressmaking. Oxford: Berg, 1999. Bloomsbury Fashion Central. Web. 18 Aug. 2016.

Burt, Emily L., and Jacqueline Atkinson. "The Relationship between Quilting and Wellbeing." Journal of Public Health 34.1 (2011): 54-59. Oxford Journals. Web. 18 Aug. 2016.

Campbell, Colin. "The Craft Consumer Culture: Craft and Consumption in a Postmodern Society." Journal of Consumer Culture 5.1 (2005): 23-42. Sage Journals. Web. 13 Mar. 2017.

Carrier, David. "Cultural Appropriation and the Arts" James O. Young Curator: The Museum Journal 52.2 (2009): 213-5. Web. 9 Jan. 2017.

Chitrakorn, Kati. "New Young Writers on Wool." The Journal of Cloth and Culture 12.3 (2014): 306-09. Taylor \& Francis Online. Web. 11 Jan. 2017.

Choi, Tsan-Ming. "Carbon Footprint Tax on Fashion Supply Chain Systems." The International Journal of Advanced Manufacturing Technology 68.1 (2013): 835-47. Springer Link. Web. 26 Feb. 2017.

Coskuner-Balli, Gokcen, and Burcak Ertimur. "Legitimation of Hybrid Cultural Products: The Case of American Yoga." Marketing Theory (2016): n. pag. Sage Journals. Web. 3 Jan. 2017.

Duncum, Paul. "Youth's Remix Culture Off and on Line." Australian Art Education 35.1/2 (2013): 10-23. EBSCOhost. Web. 24 Jan. 2017.

Hahn, Hans Peter. "Circulating Objects and the Power of Hybridization as a Localizing Strategy." Conceptualizing Cultural Hybridization. Ed. Philipp Wolfgang Stockhammer. N.p.: Springer Berlin Heidelberg, 2012. 27-42. Print.

Hemmings, Jessica. The Textile Reader. New York: Berg, 2012. Print.

"History of Canada's Wool." Canadian Co-operative Wool Growers Limited. N.p., 2014. Web. 5 Mar. 2017. 
Indigo \& Woad, Natural and Synthetic. Vancouver: Maiwa Handprints, 2016. Print.

Kantouch, A., H. El-Sayed, and A. El-Sayed. "Improvement of the Felting and Shrinking Resistance of Wool Using Environmentally Acceptable Treatments." Journal of the Textile Institute 98.1 (2007): 65-71. Scholars Portal Journals. Web. 26 Feb. 2017.

Lash, Scott, and Celia Lury. Global Culture Industry. Cambridge: Polity, 2007. Print.

Monem, Nadine Kathe. Contemporary Textiles: The Fabric of Fine Art. London: Black Dog Pub., 2008. Print.

Peach, Andrea. "What Goes around Comes Around? Craft Revival, the 1970s and Today." Craft Research 4.2 (2013): 161-79. Ingentaconnect. Web. 6 Feb. 2016.

Prain, Leanne. Strange Material: Storytelling Through Textiles. Vancouver: Arsenal Pulp, 2014. Print.

"Pure Wool Yarn by Briggs \& Little, Canada’s Oldest Woolen Mill." Briggs \& Little Woolen Mills Ltd. N.p., n.d. Web. 26 Feb. 2017.

Rose, Barbara. Magdalena Abakanowicz. New York: Harry N. Abrams, 1994. Print. Porter, Jenelle. Fibre Sculpture: 1960-Present. New York: Prestel, 2014. Print.

Sarangi, Bijaya Ketan, et al. "Biotechnological Approach for Indigo Dye Production from Natural Resources for Green Environment." The Journal of Plant Science Research 27.2 (2011): 215-27. ProQuest. Web. 15 Aug. 2016.

Splitter, Violetta, and David Seidl. "Does Practice-Based Research on Strategy Lead to Practically Relevant Knowledge? Implications of a Bourdieusian Perspective." The Journal of Applied Behavioural Science 47.1 (2011): 98-120. Scholars Portal. Web. 10 Jan. 2017.

"Synergy." Def. 1. Merriam-Webster. N.p., n.d. Web. 15 Mar. 2017.

Tutak, Mustafa, and N. Ebru Korkmaz. "Environmentally Friendly Natural Dyeing of Organic Cotton." Journal of Natural Fibers 9.1 (2012): 51-9. Web. 15 Aug. 2016.

Ullrich, Polly. Material Difference: Soft Sculpture and Wall Works. Seattle: U of Washington, 2007. Print.

Wada, Yoshiko Iwamoto. Memory on Cloth. 1st ed. Vol. 2. New York: Kodansha, 2012. Print.

Wada, Yoshiko I. "Re: Thank You \& a Question." Message to the author. 31 Jan. 2017. E-mail. 
Wada, Yoshiko Iwamoto, Mary Kellogg Rice, and Jane Barton. Shibori: The Inventive Art of Japanese Resist Dyeing. New York: Kodansha USA, 2011. Print.

Walkup, Nancy. "Kindred Kimono." School Arts 114.8 (2015): 42. Free E-Journals. Web. 14 Mar. 2017.

Wiley, Suzanne S. "Definition of Textile Designing." EHow. N.p., n.d. Web. 24 Mar. 2017.

Wilson, Matthew. "When Creative Consumers Go Green: Understanding Consumer Upcycling." Journal of Product and Brand Management 25.4 (2016): 394-99. Emerald Insight. Web. 18 Mar. 2017.

"Yardage." Maiwa. Maiwa Handprints Ltd., n.d. Web. 5 Mar. 2017.

Yazıciog lu, E. Ta, clı. "Contesting the Global Consumption Ethos: Reterritorialization of Rock in Turkey." Journal of Macromarketing 30.3 (2010): 238-53. Scholars Portal. Web. 9 Jan. 2017. 